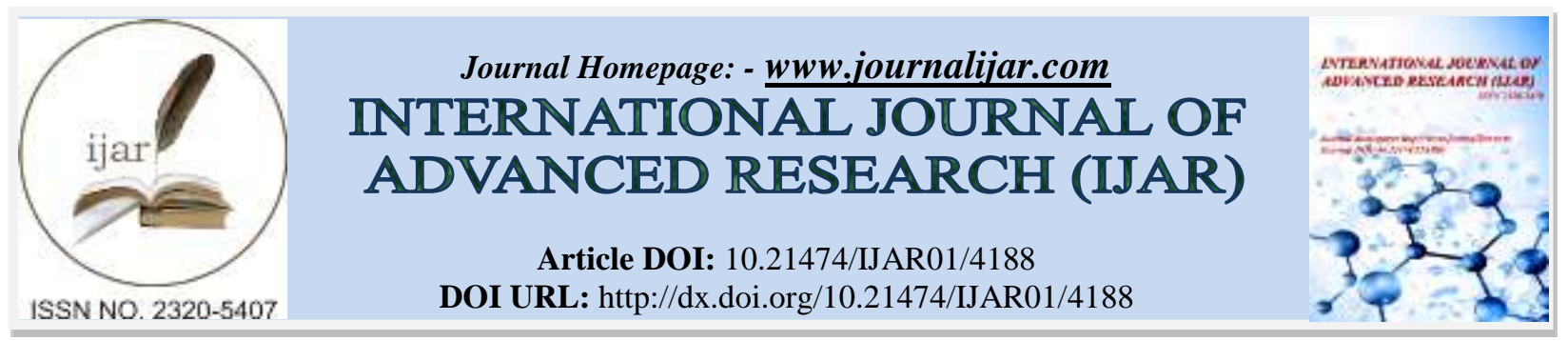

RESEARCH ARTICLE

\title{
EVALUATION OF SLAB ANALYSIS AND DESIGN PRACTICE TO ENHANCE CONSTRUCTION PROJECTS IN ETHIOPIA.
}

\section{Amanual Gebregzabher* and Xioazu Su.}

Tongji University, Department of Structural Engineering, College of Civil Engineering, 1239 siping road, Shanghai 200092, China.

\section{Manuscript Info}

Manuscript History

Received: 12 March 2017

Final Accepted: 16 April 2017

Published: May 2017

Key words:-

Design, Reliability, Safety, Slab analysis

Serviceability.

\section{Abstract}

Analysis and design of plate elements is too complex. In most cases, there is no closed form of solution for these intermediate structures. This leads full of assumptions and uncertainty which makes design uneconomical and difficult for day-to-day application. To tackle this problems, researchers and engineers developed simplified method with acceptable reliability and accuracy. Still the limitation is visible that some methods are only applicable to some particular problems. However, many professionals are claiming that the practice is not standard and may damage the economy of once country as whole if some devastating earth quake happens. As a result, care shall be taken during design, construction and service of the buildings. It is clear that buildings shall be safe, economical and serviceable. However, it is very difficult to attain these requirements in developing countries like Ethiopia. The objective of this study is to evaluate slab analysis and design practice in Ethiopia. Data was collected through document analysis and questioners. A total of 18 questioners were prepared and distributed to 45 respondents. Document analysis covers information like international and local challenges faced during analysis and design, approval and construction of slabs. It is also compares and clarifies our code of practice with respect to related international code practice and re-evaluates the country local practical, particularly in Ethiopia. About $40 \%$ of contractor and $47.7 \%$ of consultant engineers agreed that the benefits of code preparation did not considered the need for more time, finance and experience with knowledge very well. Similarly, the respondents believed that the designs are done by unqualified and unregistered engineers which suggests that codes are not implemented in day to day design analysis. Overall, Ethiopian slab analysis code needs updating by considering economic, serviceability and safety values.

Copy Right, IJAR, 2016,. All rights reserved.

\section{Introduction:-}

Slabs are important load bearing structural elements in house-building and in industrial and high-rise buildings. A very high percentage of the total volume of concrete used for the construction of buildings is used for the realization 
of slabs. During structural design, slab is the highest percentage (59\%) of load bearing followed by foundations and ground supported slabs (22\%), columns (5\%) and bearing walls (4\%) (Wight, 2009).

Elastic analysis methods: is based on elastic theory and it was introduced by (Marcus, 1924) and to analyze continuous plate system. He developed approximation solution based assumptions that, The plate is elastic web with strips located at mid-span of the plate Load shall be uniform, The neighborhood panel should not vary by more than $50 \%$, It based on aspect ratio of $1_{y} / l_{x}$ Some alternative methods, which lead to very similar results, are available. Grashof and Rankine, the tables and graphs of CZERNY; the tables of (Eleiche 1975). The other method is simple and effective for practical reinforced concrete slab analysis developed by (Pieper and Martens, 1966). In this method the field moments at the center of individual panels can be calculated by taking the average of the corresponding field moments of plates with simply supported boundary conditions and those with completely fixed edges. To simplify this method.

Assumptions, ratios of the neighboring panels are smaller than 5:1, the load shall be in the limit stated below:

$$
P_{L L} \leq \frac{1}{3} q, \quad P_{L L} \leq 2 P_{D L},
$$

Thus, the field moments at the center of plates with various types of boundary conditions can be obtained from:

Where

$$
m_{f x}=\frac{q l_{x}^{2}}{f_{x}} \quad \text { and } \quad m_{f y}=\frac{q l_{x}^{2}}{f_{y}}
$$

- $f_{x}$ and $f_{y}$ Forces and $l_{x}$ and $l_{y}$ are the shorter and loger sides of the plate respectively.

- $q$ is the sum of dead loads and live loads given by : $q=P_{D L}+P_{L L}$

For simply supported plates which are not properly anchored, one should use

$$
m_{f x}=\frac{q l_{x}^{2}}{f_{x}^{0}} \quad \text { and } \quad m_{f y}=\frac{q l_{x}^{2}}{f_{y}^{0}}
$$

Similarly, negative moments at the supports are obtained by averaging the negative moments of plates with completely fixed boundaries, provided this average value is not smaller than $75 \%$ of the largest negative moment.

Plastic analysis Method: - yields good result for deformation and stresses, it doesn't tell us the ultimate load carrying capacity of the structure at failure load, at such condition (at failure) the elastic theory become no longer valid, the other problem of elastic method is mathematically complex. Although most plate problems can be solved by numerical method using computers extensively, the yield line can be used to check computerized solutions. Hence it is an alternative computational method for RC slabs. (Kazinczy, 1914) observed that the ultimate load carrying capacity of clamed steel beam was considerably higher than the predicted by elastic theory which is due to ductility of the material.

By introducing an idealized stress strain relationship and rectangular stress pattern, the true moment capacity of the section is given by

$$
M_{u}=\int_{(A)} Z \sigma_{y} d A=\sigma_{y} \int_{\left(A_{1}\right)} Z d A-\sigma_{y} \int_{\left(A_{2}\right)} Z d A=\sigma_{y} \frac{b h^{2}}{4}
$$

Further, (Johansen, 1943) extended the ultimate load analysis of beams and frames to RC slabs by introducing the concept of yield lines, (Lin 1971) have demonstrated a good agreement between experiments and analytical solutions.

In analysis of slabs using this method depends on the patterns of yield line, the optimum failure shall be identified this can be obtained by try and error. Procedure coupled with an iterative technique and needs experience.

When distributed and concentrated loads act simultaneously on a given slab, the determination of optimum yield line pattern become quite involved. Johansen's superposition theorem can be used, the ultimate moment can be written

$$
m_{u 1}+m_{u 2}+m_{u 3}+\cdots+m_{u k}+m_{u n} \geq m_{\sum p}
$$

Where $m_{u k}$ is the ultimate moment corresponding to the $\mathrm{p}_{u k}$ (ultimate load of yield line pattern)

$m_{\sum p}$ Is the ultimate moment pertinent to the yield line pattern produced by the total load 


$$
p_{u 1}+p_{u 2}+p_{u 3}+\cdots+p_{u k}+p_{u n} \geq \sum_{n} p
$$

\section{Estimating of Deflection:-}

The approximate method of Marcus can be extended to obtained estimate of the maximum deflections produced by service loads.

(Based maximum loan deflection)

$$
w_{\max }=\frac{C M_{\max } l^{2}}{E I}
$$

Where $\mathrm{C}$ depends on the shape of the bending moment diagram, $\mathrm{C}$ is $1 / 8$ for rectangular shape $1 / 8$ to $1 / 10$ for trapezoidal $1 / 9.6$ for parabolic and $1 / 12$ for triangle shape bending moments.

However the bending moment shape for yield lines are somewhat rectangle and the elastic theory yields parabolic moment distribution to compensate this problem, we can use average of the two shapes i.e. $C=1 / 9$ therefore,

$$
w_{\max }=\frac{1}{6} \frac{M_{u} l^{2}}{E I}
$$

This can also be used for different boundary condition.

Where, $l$ is the distance between the points of zero moment

Assuming simply supported rectangular plates with uniform load the maximum deflection is given by

\section{Strip Method:-}

$$
w_{\max }=C \frac{5}{384} P_{0} l_{x}^{2}
$$

Is introduced by (Hilleborg, 1956) and developed by (Wood \& Armer, 1968) is also based on the assumption that reinforced concrete slabs behave plastically. However, the strip method, unlike yield line analysis, provides a lower bound on the collapse load. The strip technique is based on the lower bound or 'safe' theorem of plasticity. It involves finding a set of moments which are in equilibrium with the loads on the structure and which do not exceed the plastic moment capacity of the slab at any point.

The 'safe' theorem ensures that the collapse load factor associated with any statically admissible set of moments will be less than, or equal to, the true collapse load factor.

Consider the segment of slab and the associated moments and shear forces in figure below. The condition which must be satisfied for the element to be in vertical equilibrium is:

$$
\frac{\partial^{2} m_{x}}{\partial x^{2}}+\frac{\partial^{2} m_{y}}{\partial y^{2}}+2 \frac{\partial^{2} m_{x y}}{\partial x \partial y}=-q
$$

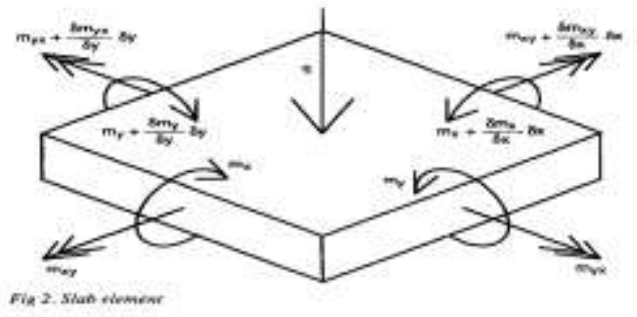

Figure 1:- forces in plate.

Where $m_{x}$ and $m_{y}$ are moments per unit length on the $\mathrm{X}$ and $\mathrm{Y}$ faces, respectively, and $m_{x y}$ presents the torsional moment per unit length. Hilleborg suggested setting the torsional term to zero and choosing $m_{x}$ and $m_{y}$ accordingly. Setting the torsional term in equation to zero gives:

This can be rewritten as

$$
\frac{\partial^{2} m_{x}}{\partial x^{2}}+\frac{\partial^{2} m_{y}}{\partial y^{2}}+0=-q
$$

$$
\frac{\partial^{2} m_{x}}{\partial x^{2}}=-\alpha q
$$


And

$$
\frac{\partial^{2} m_{y}}{\partial y^{2}}=-(1-\alpha) q
$$

Where $\alpha$ is a factor reflecting the degree of load sharing between the two orthogonal directions? Hilleborg's technique involves sharing the load at each point on the slab between two notional one-way spanning slabs which span in the reinforcement directions which are usually orthogonal as shown in Fig below.

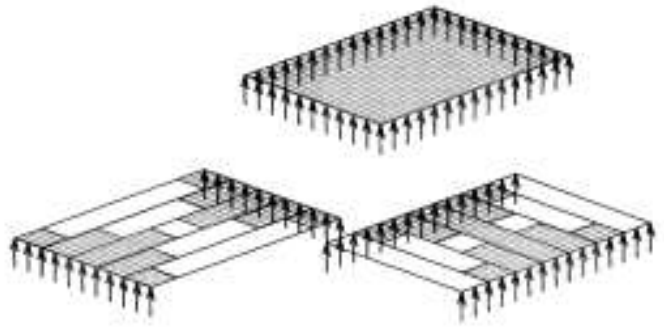

Figure 2:- slab strips

The value of $\alpha$ determines how the load is divided between the $\mathrm{X}$ and Y directions. Hilleborg's approach does not require that the load on a given element be carried by spanning exclusively in either one or the other direction. Further, the value of $\alpha$ is not restricted to being between zero and unity. However, when Hilleborg's method is applied hand, the value of $\alpha$ for each section of slab is often set to either zero or one once the load has been allocated between the notional slabs spanning the two orthogonal directions, the one-way-spanning slabs are subdivided into strips and each strip is analyzed as an independent beam. As they are assumed to behave independently, the strip with the lowest collapse load factor dictates the overall collapse load.

\section{Materials and Methods:}

\section{Data collection flow chart:-}

To evaluate the current practice of slab analysis and design in Ethiopia particularly in Addis Ababa and Mekelle cities, it will be very help full first to identify the stake holders which directly or indirectly participate in the processes of analysis, design and detailing and approval (based on legalization), construction and creating professional. These are municipality consulting firms and contractor.

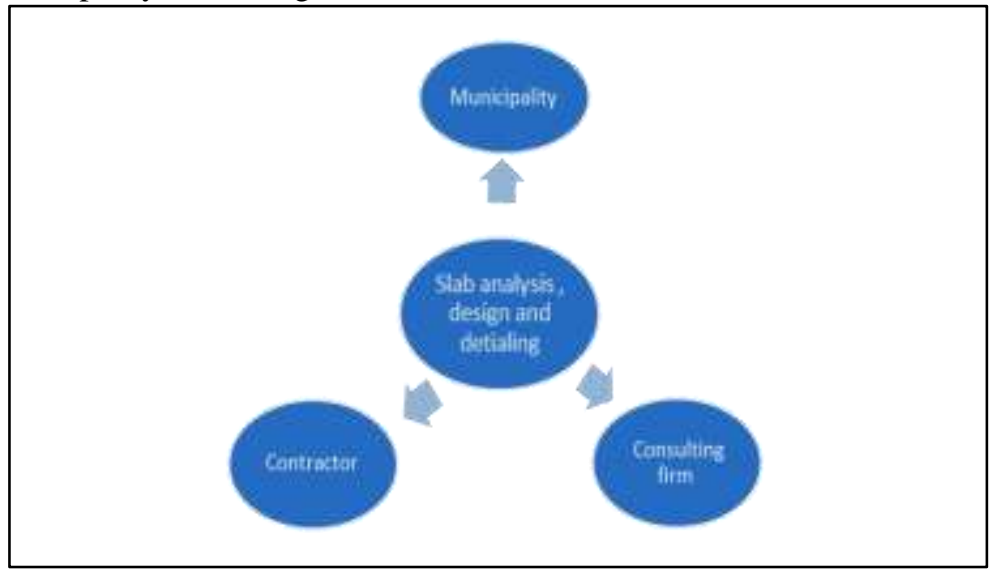

Figure 3:- Flow chart.

Data collection of practicing engineers which mainly participate in such process. Interaction engineers with engineers, engineers with code, with international knowledge and practice, these include evaluating of clarity, simplicity completeness and availability of the codes and assess the professional experience and capacity using questioners.

\section{Secondary Data Assessed:-}

Critical evaluation of design documents approved in government bodies (specifically in municipality),this covers checking whether these satisfy the methods and assumptions in analysis, design and detailing and then compare of 
the methods design based codes and other literatures considering accuracy and economic implication. Documents which are going to be assessed and evaluated in this research are classified in to three types these are;

1. Codes

2. Design report

3. Design drawings. In this case through evaluation, comparison and contrasting of our code Ethiopian building code standards (EBCS) with British standards( BS), euro code (EC), Indian standards (IS), and American concrete institute (ACI) (in relevant issues) are performed. This includes identifying similarity, differences, and assumptions. Even though there are about 5 international codes are in hand including EBCS, the codes are not latest editions. 10 samples of design report are considered.

\section{Questioner Design:-}

It is clear there are different cases, assumptions and methods of slab analysis, design and detailing and plenty question could be raised from different perspectives and practice level and experience. So about 18 representative questions, this mostly rose by professionals and thought to fulfill the general practice. These are classified as questioner for 7 Municipality engineers (ME), 7 Consultant engineers (CE), 4. Contractor engineers (CTE)

\section{Data Analysis:-}

Considering the cases of sample assessment and analysis methods specified above, the first step is code and document evaluation and then data collection using questioner. These data are recorded and analyzed using software called statistical package (SPSS version 20) and presented in a descriptive way in conjunction with all the cases

\section{Results and Discussion:- \\ Respondents Biography:-}

Out of 45 the total responding $86.7 \%$ male ,13.3\% female, $71 \%$ (19-35years) and $29 \%$ (>35years)age are 53.3\% graduate engineers (GE) and 26.6\% practicing professional structural engineer (PPST) only $20.1 \%$ are professional engineer (PE) and professional structural engineer (PST). The engineers responding $46.7 \%$ at consulting firm $17.8 \%$ contractors and 35.5\% municipality. As show in the fig. Most of the respondents were found male, GE, at the age of $19-35$ years.

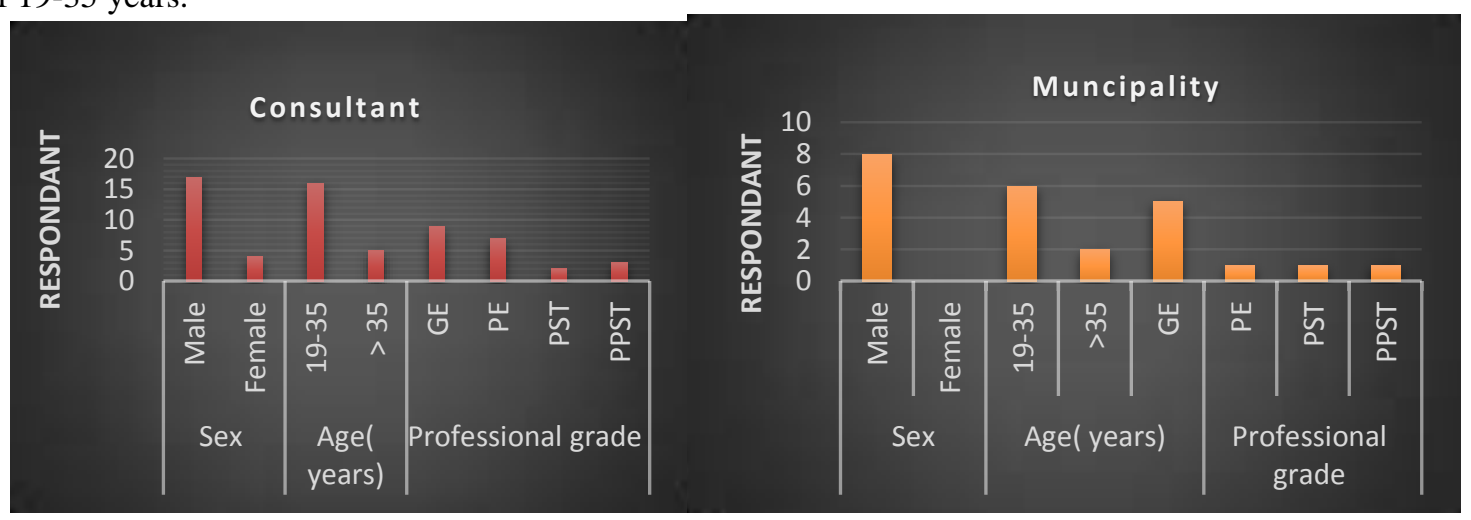

a)

b)

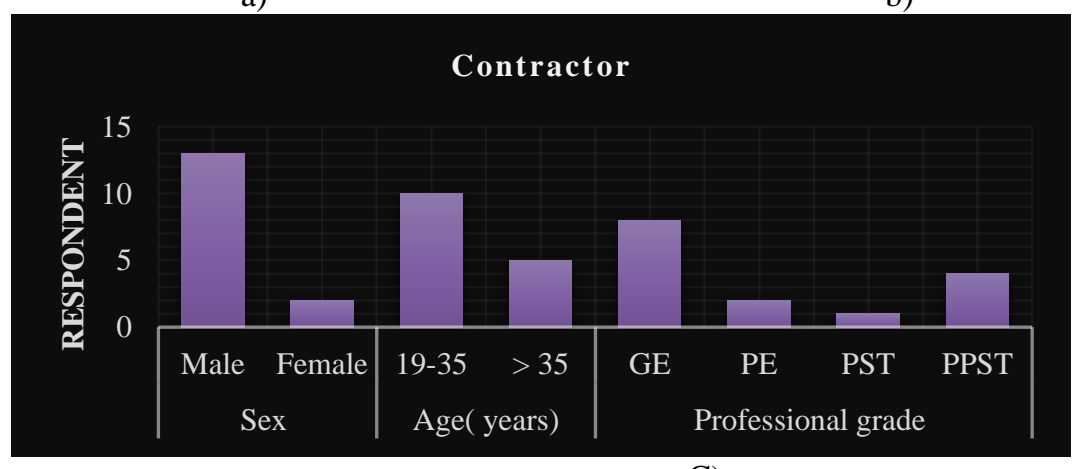

C)

Figure 4:- a), b) and C) Number of Respondents. 
The number of samples distributed $84 \%$ CE, $80 \%$ ME, 100\% CTE 100\% document codes \&design report Generally 85 samples are taken as representative samples.

Table 1:- sample size and number of samples collected.

\begin{tabular}{|l|l|l|l|}
\hline Respondents & Sample size (In number) & Sample collected & \multicolumn{2}{l|}{} \\
\cline { 3 - 4 } & & In number & $\%$ \\
\hline Consultant engineers(CE) & 25 & 21 & $84 \%$ \\
\hline Municipality engineer(ME) & 10 & 8 & $80 \%$ \\
\hline Contractor engineers (CTE) & 15 & 15 & $100 \%$ \\
\hline Document codes & 5 & 5 & $100 \%$ \\
\hline Design report & 10 & 10 & $100 \%$ \\
\hline
\end{tabular}

\section{Response for questionnaires (Discussion):-}

EBCS means the Ethiopian building code of standard. Building codes are developed and issued standard for design and construction work, and follow up and supervise the implementation thorough out the country is the same. Purpose of building codes Serve as nationally recognized document. The application which is deemed to ensure compliance of building with the minimum requirement for design, construction and quality of materials set drown by the national building code.

Benefits of the codes Harmonized of professional practice. Ensure of appropriate level of safety health and economy with due consideration of the objective condition and need of the country. Legal status of the code and its implementation as per the definition of powers and duties of the executive organs of the federal democratic republic of Ethiopia proclamation No 691/2005, the Ethiopian building code of standard (EBCS) is prepared by ministry of works and urban development. Implemented based on the Ethiopian building proclamation no. 624/2009 , council ministers of building regulation No. 243/2011 and ministry of works and urban development building regulation No.243/2003. Proclamation no. 624/2009 act No 34 (MoWUD, 1995). States how the Structure should be designed: to provide strength, stability, serviceability and durability in accordance with accepted principles of structural design. Such buildings may not exhibit signs of structural failure during their life span under normal loading.

There are many type of codes but the relevant codes for this research are stated below:

1. EBCS 1

2. EBCS 2

3. EBCS 2 part 2

Assumptions of the code In EBCS 2 section 1.1.8, "It has been assumed in the drafting of EBCS that the design of concrete structures is entrusted to register structural or civil engineers, appropriately qualified and that the execution of the work is carried out under the direction of appropriately qualified supervisors. Slab design in EBCS The slab analysis and design are put into two codes of EBCS, in which the actions (loads on slabs) are stated in EBCS 1 and the analysis and design including material property are included in EBCS 2. To have simple over view of the minimum requirement set by the codes, this study assessed the codes separately and compare with well-known codes ACI, EC, IS and BS. The two codes focus on design actions, safety and serviceability requirement of slab and other structures for the standard structural reliability.

Assumptions on EBCS Choices of structural system and the design of the structure is made by appropriately qualified and experienced personnel, Execution is carried out by personnel having the skill and experience, Adequate supervision and quality control is provided during execution of the work, i.e. in design office, factories and plants and on sites, The construction materials and products are used as specified in EBCS 1 or in EBCS 2 to 8 or in relevant supporting material or product specifications, The structure will be adequately maintained and used (give service) based on the design assumption, Design procedures are valid only when the requirements for the materials, execution and work man ship given in EBCs 2 to 8 are also complied with fundamental requirements of design in EBCS (EBS, 1995). A structure shall be designed to remain fit for the required function and sustain the actions which could occur during construction and use with appropriate degree of reliability and in an economy way during the intended life of the structure, to attain this it shall be given attention to structural safety and serviceability, including durability. The structure shall also poses a capacity to with stand, events like fire, explosion, impact or consequence of human error to an extent disproportionate to the original cause. This can be fulfilled by avoiding hazards, selecting structure with low sensitivity to hazards, selecting suitable structural form to survive accident 
removal of individual element or limited part of the structure with acceptable localized damage, avoiding sudden catastrophic failure and increasing redundancy by trying structures together.

The above requirements can also be made by the choice of suitable material, by appropriate design and detailing and with appropriate control during design construction and use. To have good reliability, the design shall satisfy the measures stated serviceability requirement representative value of action, The choice of partial safety factors or appropriate quantity of design calculation, considering durability, structural integrity, the accuracy of mechanical model, the stringency of the detailing rules In the design working life and durability to satisfy the function or purpose the building relevant design situation shall be selected (in this research) persistent situation (condition of normal use) will be considered with appropriate design life (50 years for buildings), the structure shall fits and durable for use throughout the design life with appropriate maintenance considering the environmental conditions at design stage with appropriate protection to material or product.

Looking on the benefits of code preparation $40 \%$ contractor and $47.7 \%$ consultant engineers agrees the benefits are not on the ground. Similarly, the respondents believe of the designs are done by unqualified, unregistered engineers, hence it is clear that codes are not implemented in day to day design. Those who use codes for analysis and design of slabs, more than half refers other codes $(23.8 \% \mathrm{BS}, 28.6 \% \mathrm{EC}$, and $14.3 \% \mathrm{ACI})$. In municipality engineers $50 \%$ medium, $37.5 \%$ complex and no one respondents easily understand the code easily in similar way consultant engineers $19 \%$ easy and $76.2 \%$ medium respondents to understand code this shows us codes are not understand easily (ACI, 1989).

Table 2:- Questioner and response (ME).

\begin{tabular}{|c|c|c|c|c|}
\hline Number & Item & Alternative & Frequency & $\%$ \\
\hline \multirow[t]{3}{*}{1.} & \multirow{3}{*}{$\begin{array}{l}\text { Do you know the Ethiopian Building Proclamation No. 624/2009 } \\
\text { and 243/2011? }\end{array}$} & yes & 7 & 87.5 \\
\hline & & no & 1 & 12.5 \\
\hline & & No comment & 0 & 0 \\
\hline \multirow[t]{3}{*}{2.} & \multirow{3}{*}{$\begin{array}{l}\text { Do you have in your office the Ethiopian Building code of } \\
\text { standard (EBCS)? }\end{array}$} & yes & 7 & 87.5 \\
\hline & & no & 1 & 12.5 \\
\hline & & No comment & 0 & 0 \\
\hline \multirow[t]{3}{*}{3} & \multirow{3}{*}{$\begin{array}{l}\text { The benefits of the code is harmonizing of professional practice } \\
\text { and ensure of appropriate level of safety, health and economy, do } \\
\text { you think these benefits are on the ground? }\end{array}$} & yes & 7 & 87.5 \\
\hline & & no & 1 & 0 \\
\hline & & No comment & 0 & 12.5 \\
\hline \multirow[t]{3}{*}{4} & \multirow{3}{*}{$\begin{array}{l}\text { It has been assumed during drafting of this code, the design is } \\
\text { performed by appropriately qualified registered structural or civil } \\
\text { engineers, and construction is done based on appropriately } \\
\text { qualified supervisors. Do you think this is actually happen? }\end{array}$} & yes & 7 & 87.5 \\
\hline & & no & 0 & 0 \\
\hline & & No comment & 1 & 12.5 \\
\hline \multirow[t]{3}{*}{5} & \multirow[t]{3}{*}{ Do you use codes in slab design approval? } & yes & 6 & 75 \\
\hline & & no & 2 & 25 \\
\hline & & No comment & 0 & 0 \\
\hline \multirow[t]{3}{*}{6} & \multirow{3}{*}{$\begin{array}{l}\text { In EBCS } 1 \text { section 1.1.1(6) states for which are not stated in } \\
\text { EBCS can be used from euro code, have you refer euro codes, } \\
\text { have you ever use euro codes as supporting cods? }\end{array}$} & yes & 1 & 12.5 \\
\hline & & no & 6 & 75 \\
\hline & & No comment & 1 & 12.5 \\
\hline \multirow[t]{4}{*}{7} & \multirow[t]{4}{*}{ Do you think all the codes above are easily understandable? } & easy & 0 & 0 \\
\hline & & Medium & 4 & 50 \\
\hline & & Complex & 3 & 37.5 \\
\hline & & No comment & 1 & 12.5 \\
\hline
\end{tabular}


Table 3:- Questioner and response (CE)

\begin{tabular}{|c|c|c|c|c|}
\hline Number & Item & Alternative & Frequency & $\%$ \\
\hline \multirow[t]{3}{*}{1.} & \multirow{3}{*}{$\begin{array}{l}\text { Do you know the Ethiopian Building Proclamation No. 624/2009 } \\
\text { and } 243 / 2011 \text { ? }\end{array}$} & yes & 15 & 71.4 \\
\hline & & no & 5 & 23.8 \\
\hline & & No comment & 1 & 4.8 \\
\hline \multirow[t]{3}{*}{2.} & \multirow{3}{*}{$\begin{array}{l}\text { The benefits of the code is harmonizing of professional practice } \\
\text { and ensure of appropriate level of safety, health and economy, do } \\
\text { you think these benefits are on the ground? }\end{array}$} & yes & 11 & 52.3 \\
\hline & & no & 10 & 47.7 \\
\hline & & No comment & 0 & 0 \\
\hline \multirow[t]{3}{*}{3} & \multirow{3}{*}{$\begin{array}{l}\text { It has been assumed during drafting of the code, the design is } \\
\text { performed by appropriately qualified registered structural or civil } \\
\text { engineers, and construction is done based on appropriately } \\
\text { qualified supervisors. Do you think this is actually happen? }\end{array}$} & yes & 12 & 57.1 \\
\hline & & no & 7 & 33.3 \\
\hline & & No comment & 2 & 9.6 \\
\hline \multirow[t]{3}{*}{4} & \multirow{3}{*}{$\begin{array}{l}\text { Have you ever read all the codes in detail specially slab design } \\
\text { and analysis? }\end{array}$} & yes & 12 & 57.1 \\
\hline & & no & 9 & 42.9 \\
\hline & & No comment & 0 & 0 \\
\hline \multirow[t]{3}{*}{5} & \multirow[t]{3}{*}{ Have you ever refer to Chinese standard in slab design? } & yes & 0 & 0 \\
\hline & & no & 19 & 90.5 \\
\hline & & No comment & 2 & 9.5 \\
\hline \multirow[t]{5}{*}{6.} & \multirow[t]{5}{*}{ Where do you get the simplified method? } & $\mathrm{BS}$ & 0 & 0 \\
\hline & & $\mathrm{EC}$ & 5 & 23.8 \\
\hline & & IS & 6 & 28.6 \\
\hline & & $\mathrm{ACI}$ & 3 & 14.3 \\
\hline & & No comment & 7 & 30 \\
\hline \multirow[t]{4}{*}{7} & \multirow[t]{4}{*}{ Do you think all the codes above are easily understandable? } & easy & 4 & 19 \\
\hline & & Medium & 16 & 76.2 \\
\hline & & Complex & 0 & 0 \\
\hline & & No comment & 1 & 4.8 \\
\hline
\end{tabular}

Table 4:- Questioner and response (CTE).

\begin{tabular}{|c|c|c|c|c|}
\hline Number & Item & Alternative & Frequency & $\%$ \\
\hline \multirow[t]{3}{*}{1.} & \multirow{3}{*}{$\begin{array}{l}\text { Do you know the Ethiopian Building Proclamation No. } \\
624 / 2009 \text { and } 243 / 2011 ?\end{array}$} & yes & 13 & 86.7 \\
\hline & & no & 2 & 13.3 \\
\hline & & No comment & 0 & 0 \\
\hline \multirow[t]{3}{*}{2.} & \multirow[t]{3}{*}{ Do you know the codes used for slab design? } & yes & 14 & 93.3 \\
\hline & & no & 1 & 6.7 \\
\hline & & No comment & 0 & 0 \\
\hline \multirow[t]{3}{*}{3} & \multirow{3}{*}{$\begin{array}{l}\text { The benefits of the code is harmonizing of professional } \\
\text { practice and ensure of appropriate level of safety, health } \\
\text { and economy, do you think these benefits are on the } \\
\text { ground? }\end{array}$} & yes & 9 & 60 \\
\hline & & no & 6 & 40 \\
\hline & & No comment & 0 & 0 \\
\hline \multirow[t]{3}{*}{4} & \multirow{3}{*}{$\begin{array}{l}\text { It has been assumed during drafting of this code, the } \\
\text { design is performed by appropriately qualified registered } \\
\text { structural or civil engineers, and construction is done } \\
\text { based on appropriately qualified supervisors. Do you think } \\
\text { this is actually happen? }\end{array}$} & yes & 9 & 60 \\
\hline & & no & 6 & 40 \\
\hline & & No comment & 0 & 0 \\
\hline
\end{tabular}

Slabs are classifies as one way, ribbed slab and two ways and waffle slab and flat slabs based on their structural behavior. Analysis of one way slab Linear elastic method, plastic and nonlinear analysis for ultimate limit state and only elastic method for serviceability limit state are proposed for analysis of one way slab. The analysis of one way slab is carried out similar to beam of one meter width. This code doesn't specify any simplified method of analysis for this type of slab.

Criteria for slab EBCS2 defines a structure to be treated as slab having side dimensions of $a$ and $d$ and thickness of $\mathrm{h}$, the least side dimension shall be greater than 4times the thickness of the slab. Criteria for one way slab either the 
slab is supported by two opposite and parallel sides of beams where the other two parallel sides are free of support or slab supported on four sides with the ratio of the longer span to shorter span is greater than 2.Moment redistributions the maximum moment redistribution allowed in the part one of code is $25 \%$, on the contrary EBCS 2 part 2 states the maximum percent of redistribution is 30 . The elastic linear analysis may be reduced by the reduction factor $(\delta)$ given in equation (14) of the code,

$$
\delta=\left\{\begin{array}{c}
k_{1}+k_{2}\left(\frac{x_{u}}{d}\right), \text { for } \frac{l}{d} \leq 20 \text { and continouse beam } \\
0.75, \text { for other continouse beam } \\
0.9, \quad \text { for sway frames }
\end{array}\right.
$$

Table 5:- Moment redistribution of different codes.

\begin{tabular}{|c|c|c|c|}
\hline Code & $k_{1}$ & $k_{2}$ & Maximum redistribution $\delta^{\prime}($ in $\%)$ \\
\hline EBCS & 0.44 & 1.25 & 25 \\
\hline BS & 0.4 & 1 & 20 \\
\hline EC & 0.44 & 1.25 & 30 \\
\hline IS & 0.6 & 1 & 20 \\
\hline ACI & \multicolumn{2}{|c|}{$\left(1000 \varepsilon_{t}\right)$} & \\
\hline
\end{tabular}

Table 6:- Span of depth ration of one way slabs.

\begin{tabular}{|c|c|c|c|c|}
\hline \multicolumn{2}{|c|}{ Span to effective depth ratio of one way slabs } \\
\hline Support condition & \multicolumn{3}{|c|}{$\mathrm{f}_{\mathrm{yk}}$} \\
\cline { 2 - 6 } & 300 & 400 & 460 & 500 \\
\hline Simply supported & 24 & 20 & 18 & 21 \\
\hline End span & 28 & 24 & 22 & 24 \\
\hline Interior span & 33 & 28 & 26 & 9 \\
\hline Cantilevers & 12 & 10 & 9 & \\
\hline
\end{tabular}

This table is based on the deflection equation of EBCS 2. However, the equation doesn't specify up to what span is applicable. The reduced moment can be calculated as $M_{p}=\delta M_{e}$. Moreover, to avoid catastrophic sudden failure of concrete crush and initiate extended ductile failure (tension control) the section shall be under reinforced, to satisfy this code limits the relative neutral axis depth of a section based on the amount of moment redistributions and is given in equation 9 of EBCS 2 part 2.

$$
k_{x}=\frac{x}{d}=0.8(\delta-0.44)
$$

Where

$$
\delta=\frac{100-\% \text { of redistrubition }}{100}
$$

As discussed above the maximum redistribution is $25 \%$ hence the maximum redistribution moment reduction multiplier $(\delta)$ will be 75, and summarized as follows: Table relative Neutral axis depth for different redistribution of moment as per EBCS at ULS

Table 7:- relative Neutral axis depth for different redistribution of moment as per EBCS at ULS

\begin{tabular}{|c|c|c|}
\hline \%of redistribution & $\delta$ & $k_{x}$ \\
\hline 0 & 100 & 0.448 \\
\hline 10 & 90 & 0.368 \\
\hline 20 & 80 & 0.288 \\
\hline 25 & 75 & 0.248 \\
\hline
\end{tabular}

Analysis of two way slab supported on four sides with the ratio of the longer span to shorter span is less than 2

Method of analysis the code proposes linear analysis with or without moment redistribution, plastic analysis, and nonlinear analysis. But focuses only in the first two methods, the nonlinear method analysis of slabs is not covered. The elastic linear analysis method is based on gross cross-section with Poisson's ratio of between 0 and 0.2 and is applicable for both ultimate and serviceable limit states. Similar to the one way slabs, the maximum percent of redistribution of moment is 25\%. A linear elastic analysis (as said in EBCS 2 but not said in other cods and completely wrong) of slabs based on moment coefficient (which is rather derived from modified yield line as 
described below) is proposed in of EBCS 2 (EBS, 1995). Redistribution is not allowed for this method and it is only applied to rectangular slabs.

\section{Assumptions:-}

a) Concentrated load (partition load) on one way slabs (EBCS sec A.3.1. (2))

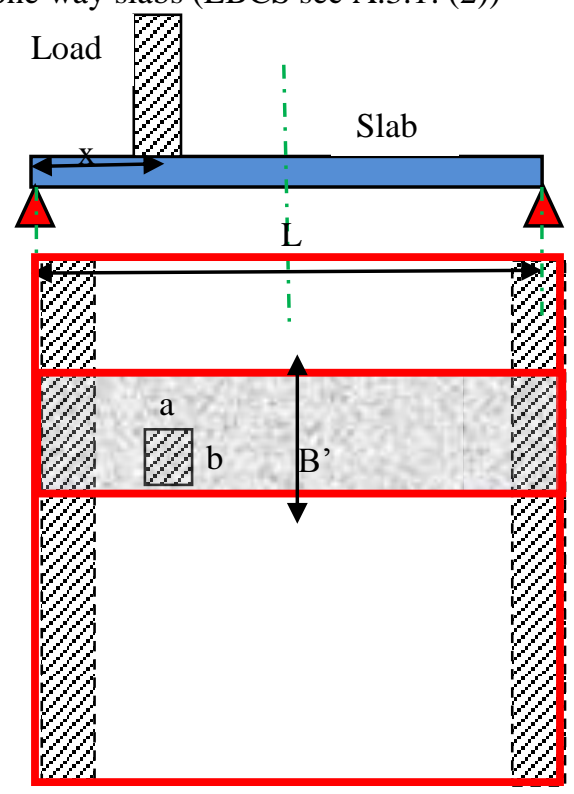

Figure 5:- distribution of concentrated load on one way slabs

Effective width $\left(B^{\prime}\right)$ carrying a concentrated load can be taken as (considering load width $(b)$ )

$$
B^{\prime}=b+2.4 x\left(1-\frac{x}{l}\right) / l \ldots(17)
$$

If the distance from the face of load to free end is less than $30 \%$ for the span of the slab which is under consideration.

On two way slabs (EBCS sec A.3.1. (2)) the supporting wall or beams are assumed as unyielding and the minimum thickness of the supporting beam shall be as given in section A.3.1 (1) can be given by;

$$
\begin{array}{r}
h_{1} \geq 2.5 h_{s} \frac{l_{1}}{l_{x}} \\
h_{2} \geq\left\{\begin{array}{c}
2.5 h_{s} \frac{l_{2}}{l_{y}} \\
2.5 h_{s} \frac{l_{2}}{1.5 l_{x}}
\end{array}\right.
\end{array}
$$

Where $h_{1}$ and $l_{1}$ the depth and clear span of the beam parallel tol $l_{x}$, similarly $h_{2}$ and $l_{2}$ the depth and clear span of the beam parallel to $l_{y}$ and $h_{s}$ is the thickness of the slab. This indicates the slab and the beam shall not deflect the same. But rather the slab shall deflect leaving the beam intact leads the beam will almost the entire shear come from loads and slab will not designed for shear only check is needed. On the contrast, if the beam is not unyielding (such as hidden beam in slab very common practice) it will be flexible and both slab and the beam could fail or deflect excessively. This violates the assumption considered during derivation of the methods (such as coefficient method, yield line method and strip method). 


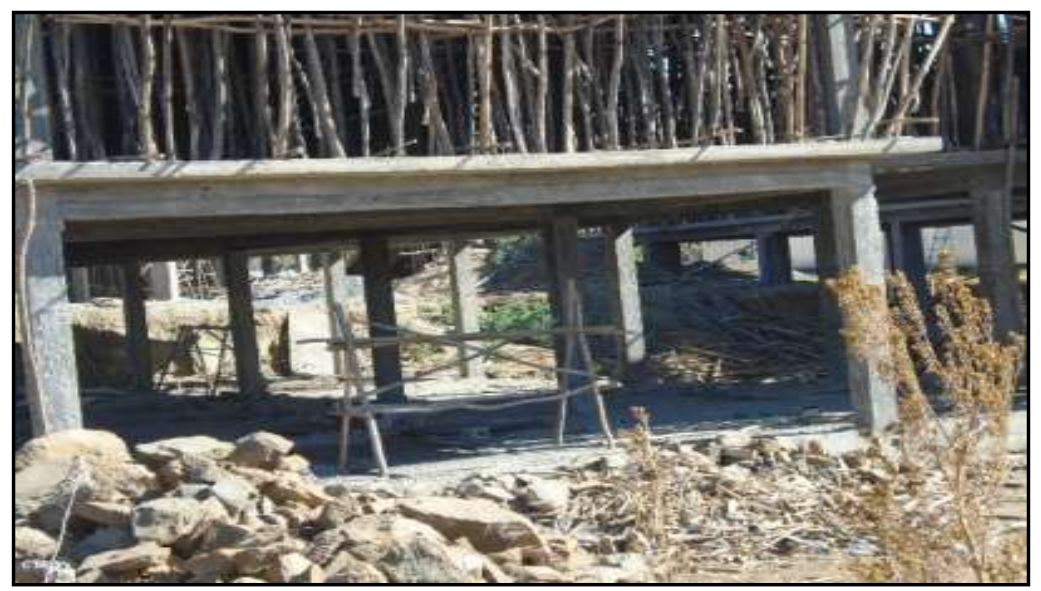

Figure 6:- Visible (4cm) deflection due to small beam Depth.

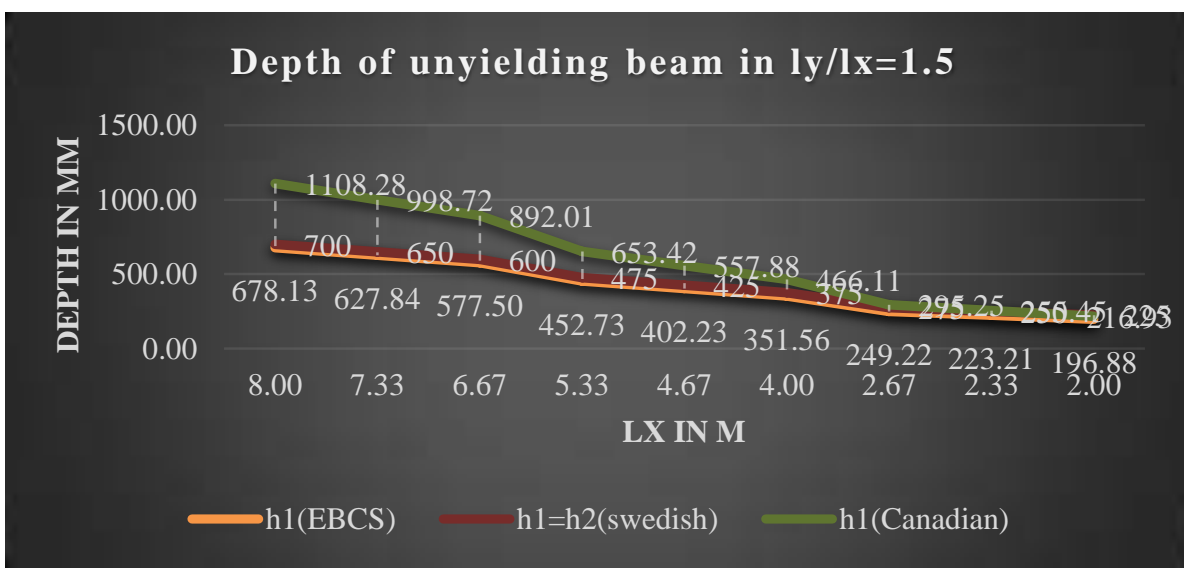

Figure 7:- Depth of unyielding beam in ly/lx=1.5.

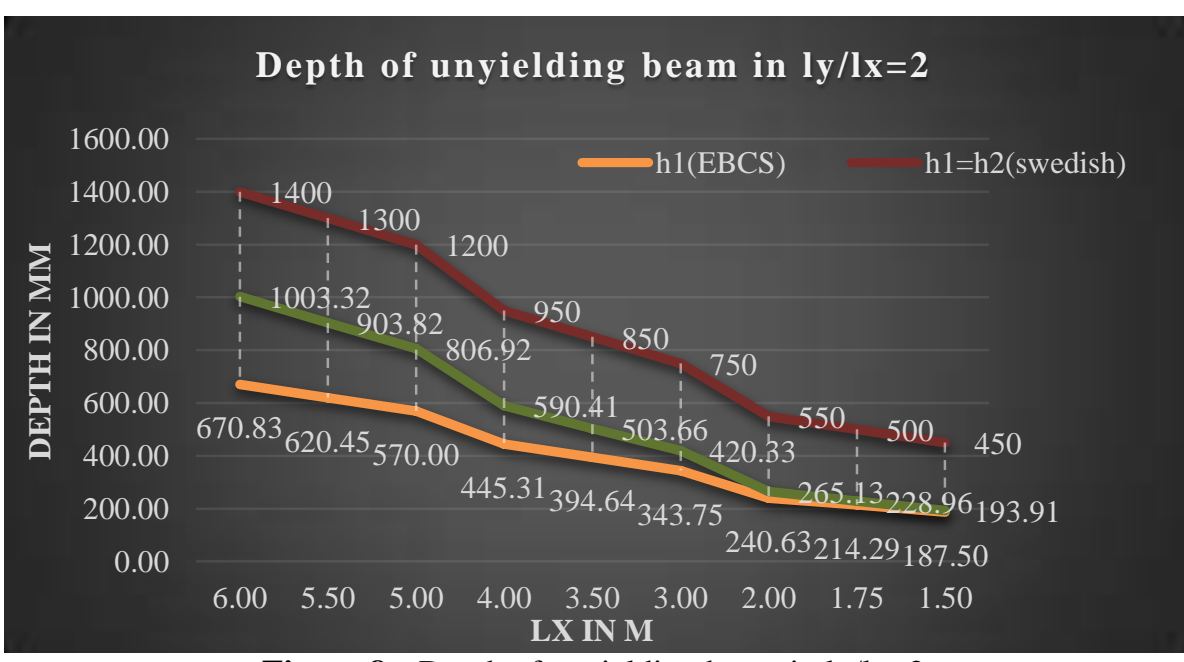

Figure 8:- Depth of unyielding beam in ly/lx=2

In the above charts the depth for unyielding beam in EBCS is smaller as compare to Swedish and Canadian code this is totally neglected in design and mostly deflections are visible during stripping of form work, but latter they fill it using plastering and cement screed (EC, 2002). Moreover, in most cases terrazzo spall away special at the center and at periphery of the slab due to excessive deflection of slab as shown in the photo, practically $4 \mathrm{~cm}$ deflection is 
observed in a slab of 4 by $8 \mathrm{~m}$ slab with beam depth of $500 \mathrm{~mm}$. where from fig. 7 above the depth of unyielding beam was estimated $445.31 \mathrm{~mm}$ in EBCS, $590.41 \mathrm{~mm}$ in Swedish code and $950 \mathrm{~mm}$ in Canadian code, which indicates EBCS 2 underestimates the depth of the beam and the deflection might increase if the depth were used based on EBCS equation .but however further study is needed to see the shear participation of the slab and beam.

The slab load shall be uniformly distributed over the area; even partition load, if these meets the criteria set in section A.3.1 (2) of the code. The point or line load shall converted to equivalent uniformly distributed load using approximate rules provided that

$$
F_{D(\text { partition })} \leq 0.2 F_{(\text {DL(including partition })+L L)}
$$

To verify this, a sample slab of $6 \mathrm{~m}$ by $7 \mathrm{~m}$ is taken and with HCB partition walls of $20 \mathrm{~cm}$ and $15 \mathrm{~cm}$ thick and $3 \mathrm{~m}$ high is taken as shown in the figure. The analysis is done by yield line method using virtual work method. It is done by varying the partition wall and live load for two cases.

\begin{tabular}{|l|l|}
\hline$\cdot$ Slab depth & $\mathbf{1 5 . 0 0}$ \\
\hline$\cdot$ Live load & $\mathbf{5 . 0 0}$ \\
\hline$\cdot \mathrm{L}_{\mathrm{x}}$ & $\mathbf{6}$ \\
\hline$\cdot \mathrm{L}_{\mathrm{y}}$ & $\mathbf{7}$ \\
\hline$\cdot$ Concrete grade & $\mathbf{C - 2 5}$ \\
\hline$\cdot$ Steel grade & $\mathbf{S - 3 0 0}$ \\
\hline$\cdot$ Assume isotropic reinforcement in both direction & \\
\hline$\cdot 45^{\circ}$ yield line bisects the slab & \\
\hline
\end{tabular}

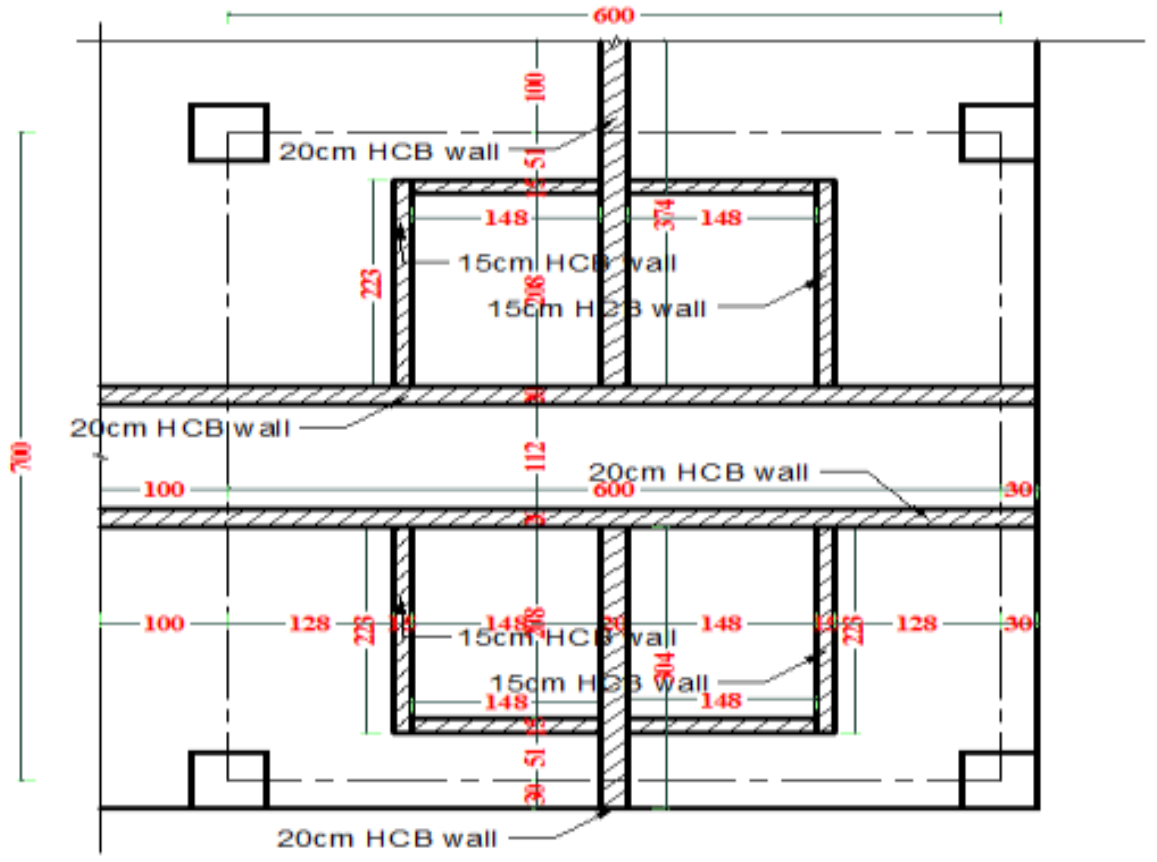

Figure 9:- Sample slab plan and design data.

a) Actual Line load is placed in its location and analyzed using virtual work of yield line method.

b) The total wall load is distributed over the area

The spread sheet used for analysis is developed based on virtual work method (yield line method). 
Table 8: Partition load analysis and comparison.

\begin{tabular}{|c|c|c|c|c|c|c|c|c|c|c|}
\hline & \multicolumn{3}{|l|}{ Loading } & \multirow[b]{2}{*}{$\begin{array}{l}\% \quad \mathrm{WL} \text { to } \\
\mathrm{TL}(\mathrm{TEW}+\mathrm{LL}) \\
\left(\mathrm{kN} / \mathrm{m}^{2}\right)\end{array}$} & \multicolumn{3}{|c|}{$\mathrm{m}(\mathrm{kNm})$} & \multicolumn{3}{|c|}{ m' (kNm) } \\
\hline $\begin{array}{l}\text { Live } \\
\text { load } \\
\left(\mathrm{kN} / \mathrm{m}^{2}\right)\end{array}$ & $\begin{array}{l}\text { Wall } \\
(\mathrm{LL})( \\
\left.\mathrm{kN} / \mathrm{m}^{2}\right)\end{array}$ & $\begin{array}{l}\text { Total } \\
\text { excluding } \\
\text { wall } \\
(\mathrm{TEW})( \\
\left.\mathrm{kN} / \mathrm{m}^{2}\right)\end{array}$ & $\begin{array}{l}\text { Total } \\
\left(\mathrm{kN} / \mathrm{m}^{2}\right)\end{array}$ & & $\begin{array}{l}\text { Case } \\
\text { "a" }\end{array}$ & $\begin{array}{l}\text { Case } \\
\text { "b" }\end{array}$ & $\%$ error & $\begin{array}{l}\text { Case } \\
\text { "a" }\end{array}$ & $\begin{array}{l}\text { Case } \\
\text { "b" }\end{array}$ & $\%$ error \\
\hline \multirow[t]{6}{*}{2} & 12.06 & 10.24 & 22.30 & $54 \%$ & 25.33 & 24.79 & $2.141 \%$ & 33.78 & 33.06 & $2.141 \%$ \\
\hline & 11.05 & 10.24 & 21.29 & $52 \%$ & 24.42 & 23.86 & $2.276 \%$ & 32.56 & 31.82 & $2.276 \%$ \\
\hline & 9.26 & 10.24 & 19.50 & $47 \%$ & 23.41 & 22.88 & $2.262 \%$ & 31.21 & 30.50 & $2.262 \%$ \\
\hline & 8.42 & 10.24 & 18.66 & $45 \%$ & 22.29 & 21.36 & $4.202 \%$ & 29.72 & 28.47 & $4.202 \%$ \\
\hline & 4.02 & 10.24 & 14.26 & $28 \%$ & 15.89 & 14.95 & $5.927 \%$ & 21.19 & 19.94 & $5.927 \%$ \\
\hline & 0.00 & 10.24 & 10.24 & $0 \%$ & 10.63 & 10.63 & $0.000 \%$ & 14.18 & 14.18 & $0.000 \%$ \\
\hline \multirow[t]{6}{*}{3} & 12.06 & 11.84 & 23.90 & $50 \%$ & 26.66 & 26.77 & $-0.391 \%$ & 35.55 & 35.69 & $-0.391 \%$ \\
\hline & 11.05 & 11.84 & 22.89 & $48 \%$ & 25.75 & 25.83 & $-0.301 \%$ & 34.33 & 34.44 & $-0.301 \%$ \\
\hline & 9.26 & 11.84 & 21.10 & $44 \%$ & 24.74 & 24.92 & $-0.734 \%$ & 32.98 & 33.22 & $-0.734 \%$ \\
\hline & 8.42 & 11.84 & 20.26 & $42 \%$ & 23.62 & 23.27 & $1.501 \%$ & 31.50 & 31.02 & $1.501 \%$ \\
\hline & 4.02 & 11.84 & 15.86 & $25 \%$ & 17.22 & 16.43 & $4.582 \%$ & 22.96 & 21.91 & $4.582 \%$ \\
\hline & 0.00 & 11.84 & 11.84 & $0 \%$ & 11.96 & 11.96 & $0.000 \%$ & 15.95 & 15.95 & $0.000 \%$ \\
\hline \multirow[t]{6}{*}{4} & 12.06 & 11.84 & 23.90 & $50 \%$ & 26.66 & 26.77 & $-0.391 \%$ & 35.55 & 35.69 & $-0.391 \%$ \\
\hline & 11.05 & 11.84 & 22.89 & $48 \%$ & 25.75 & 25.83 & $-0.301 \%$ & 34.33 & 34.44 & $-0.301 \%$ \\
\hline & 9.26 & 11.84 & 21.10 & $44 \%$ & 24.74 & 24.92 & $-0.734 \%$ & 32.98 & 33.22 & $-0.734 \%$ \\
\hline & 8.42 & 11.84 & 20.26 & $42 \%$ & 23.62 & 23.27 & $1.501 \%$ & 31.50 & 31.02 & $1.501 \%$ \\
\hline & 4.02 & 11.84 & 15.86 & $25 \%$ & 17.22 & 16.43 & $4.582 \%$ & 22.96 & 21.91 & $4.582 \%$ \\
\hline & 0.00 & 11.84 & 11.84 & $0 \%$ & 11.96 & 11.96 & $0.000 \%$ & 15.95 & 15.95 & $0.000 \%$ \\
\hline \multirow[t]{6}{*}{5} & 12.06 & 15.04 & 27.10 & $45 \%$ & 29.32 & 30.72 & $-4.766 \%$ & 39.10 & 40.96 & $-4.766 \%$ \\
\hline & 11.05 & 15.04 & 26.09 & $42 \%$ & 28.41 & 29.75 & $-4.732 \%$ & 37.88 & 39.67 & $-4.732 \%$ \\
\hline & 9.26 & 15.04 & 24.30 & $38 \%$ & 27.39 & 29.00 & $-5.855 \%$ & 36.53 & 38.67 & $-5.855 \%$ \\
\hline & 8.42 & 15.04 & 23.46 & $36 \%$ & 26.28 & 27.09 & $-3.081 \%$ & 35.04 & 36.12 & $-3.081 \%$ \\
\hline & 4.02 & 15.04 & 19.06 & $21 \%$ & 19.88 & 19.40 & $2.432 \%$ & 26.51 & 25.86 & $2.432 \%$ \\
\hline & 0.00 & 15.04 & 15.04 & $0 \%$ & 14.62 & 14.62 & $0.000 \%$ & 19.49 & 19.49 & $0.000 \%$ \\
\hline
\end{tabular}

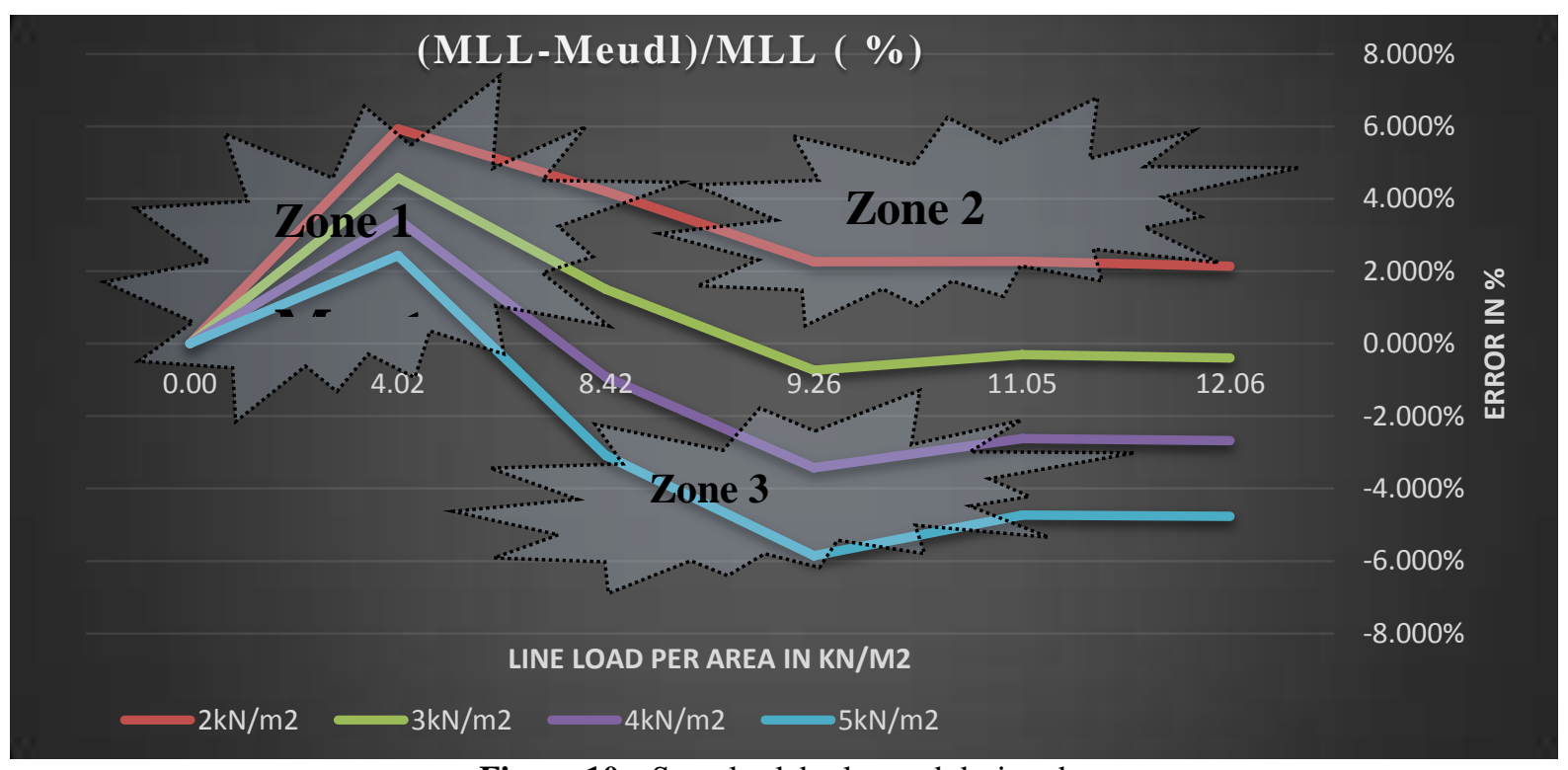

Figure 10:- Sample slab plan and design data. 
The graph above shows the error of bending moment due to replacing the line load (wall load) with equivalent uniformly distributed load.

$$
\begin{gathered}
w_{\text {eudl }}=\sum w_{l l} / A \\
w_{\text {Total }}=1.3 w_{\text {eudl }}+w_{1.3 D L+1.6 L L} \\
\operatorname{Error}(\%)=\left(M_{L L}-M_{\text {eudl }}\right) / M_{\text {eudl }}
\end{gathered}
$$

Hence, the graph shows three Zones for this particular example (the worst case support condition in order to exaggerate the result)

Zone1:- Wall load is very small which accounts 0 to $28 \%$ of the total load, indicates the estimation line load by simple equivalent uniform distributed load gives bit higher result $(0$ to $6 \%)$ as compare to actual line load. In this Zone the error at wall load of $4.02 \mathrm{kN} / \mathrm{m}^{2}$, the error is higher for smaller live load. Here the assumption safe but uneconomical.

Zone2:- Wall load is medium to high which accounts greater than $28 \%$ and live is $2 \mathrm{kN} / \mathrm{m}^{2}$, hence, the error is in the safe side, relatively economical as compared to Zone 1.

Zone3:- Wall load is medium to high which accounts greater than $28 \%$ and live is 3 to $5 \mathrm{kN} / \mathrm{m}^{2}$, hence, the error is in the un-safe side(i.e. the equivalent uniformly distributed load underestimates the moment 0 to $6 \%$, as the live load becomes higher the estimation will gain larger error. Hence, work method of wall load as line load shall be used.

\section{Conclusion:-}

We can conclude the general practice of analysis of structures particularly slab, as described and presented above is not standard, well organized and controlled. The codes lack consistency for these are not derived from one code and include unclear part which lack of commentary and supporting publications and references. Moreover, it stays long about 21years without updating revisions and never incorporates customer fed back. Some parts of the code are difficult to verify and use because it not clear form where those are referenced. Weakness in controlling and applying the proclamation and codes by government body. Which shows Lack of awareness of clients about the design and its consequence. Lack of practicing engineers to updating to latest knowledge and information, and weak in fighting illegal designers who break the market.

Due to the result of poor analysis and design and its control together with poor construction quality, buildings have been failing. Most of the building failures specially slab area changed or covered as soon as possible. Most the respondents agree that they experience slab failure. Hence, we can finally conclude that the practice of analysis and design of slab and other structures is not in good position and leads to a very visible danger to occupants and stake holders including government.

\section{Reference:-}

1. ACI, 1989. "Commentary on Building Code Requirements for Reinforced Concrete (ACI 318-89)", American Concrete Institute, Detroit, Michigan.

2. Hillerborg Jamvidsteori för armerade betong-plattor, 1956. Equilibrium theory for reinforced concrete slabs) Betong, 41 (4), pp. 177-186.

3. British standard institution (EC). Euro code 1, 2002 "Action on structures- part 1: general riles and rules for building. PrEN 1991-1-1(draft stage)", BSI, London.

4. British Standards Institution (BI), 1985 "Structural Use of Concrete: Part 1: Code of Practice for Design and Construction BS 8110: Part 1: 1985”, British Standards Institution, London.

5. Eleiche, A.M., 1975. Impedance matching in non-homogeneous elastic bars. Journal of Physics D: Applied Physics, 8, pp.505-511.

6. James G. MacGregor and James K. Wight, 2005, “Reinforced Concrete Mechanics and Design”, prentice hall, Singapore.

7. Johansen, K.W., 1962 "Yield Line Theory, (translated from the Danish)" Cement and Concrete Association, London,

8. Johansen, 1943. Extended the ultimate load analysis of beams and frames to RC slabs

9. Kazinczy, 1914. "Tests with Fixed-Ended Beams, Betonszemle, Vol. 2.

10. Lin, T.H., 1971. Physical Theory of Plasticity. In pp. 255-311. Available at: 
http://linkinghub.elsevier.com/retrieve/pii/S0065215608703442.

11. Marcus, 1924. Theory of Elasticity and Plasticity. Plate analysis, Floor and deck slabs Available on: https://www.scribd.com/document/67774621/Lecture-9-Plate-Analysis

12. Ministry of Works and Urban Development (MoWUD), 1995. "Ethiopian Building code standard.

13. Pieper and Martens, 1966. Concrete (related software). Accessed on May 6, 2017 http://www.structuralwiki.org/en/Concrete_(related_software).

14. Wood RH, Armer GST, 1968. The theory of the strip method for design of slabs. Proceedings of the Institution of Civil Engineers, vol. 41, p. 285-307

15. Wight, 2008. Slabs: linear elastic analysis. Available at: https://www.scribd.com/document/124883786/courseEC2-Chap11

16. Ying Tian, 2007, "Behavior and Modeling of Reinforced Concrete Slab Column Connections". The University of Texas, Austin. 